\title{
Radiation exposure to the eyes and thyroid during C-arm fluoroscopy-guided cervical epidural injections is far below the safety limit
}

\author{
Eun Joo Choi ${ }^{1}$, Gwangcheol Go ${ }^{1}$, Woong Ki Han ${ }^{1}$, and Pyung-Bok Lee ${ }^{1,2}$ \\ 'Department of Anesthesiology and Pain Medicine, Seoul National University Bundang Hospital, Seongnam, Korea \\ 2Department of Anesthesiology and Pain Medicine, Seoul National University College of Medicine, Seoul, Korea
}

Received October 21, 2019

Revised October 23, 2019

Accepted October 23, 2019

\author{
Correspondence \\ Pyung-Bok Lee \\ Department of Anesthesiology and Pain \\ Medicine, Seoul National University \\ Bundang Hospital, 82 Gumi-ro 173beon- \\ gil, Bundang-gu, Seongnam 13620, \\ Korea \\ Tel: +82-31-787-7499 \\ Fax: +82-31-787-4063 \\ E-mail: painfree@snubh.org
}

Previous presentation at conferences: The 59th Korean Pain Society Scientific Meeting \& Training Course, 22nd Nov. 2014, Seoul Grand Hilton Convention Center, Seoul, Korea.
Background: The aim of this study was to evaluate radiation exposure to the eye and thyroid in pain physicians during the fluoroscopy-guided cervical epidural block (CEB).

Methods: Two pain physicians (a fellow and a professor) who regularly performed Carm fluoroscopy-guided CEBs were included. Seven dosimeters were used to measure radiation exposure, five of which were placed on the physician (forehead, inside and outside of the thyroid protector, and inside and outside of the lead apron) and two were used as controls. Patient age, sex, height, and weight were noted, as were radiation exposure time, absorbed radiation dose, and distance from the X-ray field center to the physician.

Results: One hundred CEB procedures using C-arm fluoroscopy were performed on comparable patients. Only the distance from the X-ray field center to the physician was significantly different between the two physicians (fellow: $37.5 \pm 2.1 \mathrm{~cm}$, professor: $41.2 \pm 3.6 \mathrm{~cm}, P=0.03$ ). The use of lead-based protection effectively decreased the absorbed radiation dose by up to $35 \%$.

Conclusions: Although there was no difference in radiation exposure between the professor and the fellow, there was a difference in the distance from the X-ray field during the CEBs. Further, radiation exposure can be minimized if proper protection (thyroid protector, leaded apron, and eyewear) is used, even if the distance between the X-ray beam and the pain physician is small. Damage from frequent, low-dose radiation exposure is not yet fully understood. Therefore, safety measures, including lead-based protection, should always be enforced.

Key Words: Anesthesia, Epidural; Cervical Vertebrae; Chronic Pain; Eye; Fluoroscopy; Physicians; Protection, Radiation; Thyroid Gland

\section{INTRODUCTION}

Over the past 10 years, the number of interventional pain procedures using a fluoroscope has increased exponentially [1] because fluoroscopy is essential for accurate pro- cedures with minimal complications. As a result, there has been a growing concern about occupational radiation exposure [2-4]. When an epidural block is performed without fluoroscopy (i.e., blind technique; loss-of-resistance [LOR] method), there is a $13 \%-30 \%$ chance for the needle to be (c) This is an open-access article distributed under the terms of the Creative Commons Attribution Non-Commercial License (http://creativecommons.org/licenses/by-nc/4.0/), which permits unrestricted non-commercial use, distribution, and reproduction in any medium, provided the original work is properly cited.

(c) The Korean Pain Society, 2020
Author contributions: Eun Joo Choi: Writing/manuscript preparation; Gwangcheol Go: Writing/manuscript preparation; Woong Ki Han: Data curation; Pyung-Bok Lee: Study conception. 
misplaced outside of the epidural space $[5,6]$.

The cervical epidural block (CEB) is often used to treat patients with cervical herniated intervertebral discs and spinal stenosis $[7,8]$. When CEB is performed, it is essential to practice caution because the epidural space is narrower than the space in other locations, and severe complications, including spinal cord injury and paraplegia, can occur [9-11]. Therefore, CEB needle insertions must be performed under fluoroscopic guidance to practice utmost caution for ensuring an accurate procedure. Unfortunately, this places the pain physician's head near the fluoroscope, placing the physician's eyes and thyroid at a higher risk of radiation exposure compared with other techniques (Fig. 1).

Hiroshima, Nagasaki, and Chernobyl nuclear disaster survivors [12-14] and physicians of interventional cardiology $[15,16]$ and radiology $[17,18]$ have shown a higher risk of cataract development as a direct result of crystalline lens radiation exposure. Subsequently, the International Commission on Radiological Protection (ICRP) lowered the yearly maximum radiation dose to the eye from 150 to $20 \mathrm{mSv}$ [19]. The yearly maximum radiation dose to the thyroid remains at $500 \mathrm{mSv}$ [20].

Even though the dangers of radiation exposure are being continuously re-evaluated, no study has reported the risk of radiation exposure for pain physicians performing CEB. Therefore, the primary objectives of this study were to measure actual radiation exposure to a pain physician's eyes and thyroid during CEB to reveal the risks of radiation exposure and to determine the need for radiation protection. Secondary study objectives were to examine the efficacy of lead-based protection in minimizing radiation exposure and to compare radiation exposure between two pain physicians with different experience levels.

\section{MATERIALS AND METHODS}

This prospective study was approved by the Institutional Review Board of Seoul National University Bundang Hospital (No. B-1407/258-002) and was registered in the Clini- cal Research Information Service (No. KCT0001292). All study conduct adhered to the tenets of the Declaration of Helsinki, and all study subjects provided written informed consent to participate in the study.

\section{Subjects}

This study examined head and neck radiation exposure over 2 months (October and November 2014) in pain physicians performing CEB. Study subjects included a highly experienced professor ( $>2,000$ CEB cases over 4 years, height $171.5 \mathrm{~cm}$, and weight $68 \mathrm{~kg}$ ) and a relatively inexperienced fellow (approximately 100 cases over 3 months of training, height $175.3 \mathrm{~cm}$, and weight $72 \mathrm{~kg}$ ). Before their CEBs, patients were randomized into two groups using a computer-generated random list by independent physicians (nurses from the operating room). One group received CEBs carried out by the fellow and the other group by the professor.

\section{Lead-based radiation protection}

The physicians wore a lead thyroid protector and a lead apron during all procedures. The thyroid protector was a conventional collar $(0.5 \mathrm{~mm}$ lead $)$ that sufficiently covered the region between the sternal notch and the chin when properly worn. The lead apron was the coat type and was made of $0.3 \mathrm{~mm}$ lead in the front and $0.25 \mathrm{~mm}$ lead in the back. The apron provided 360 degrees of shielding over the upper thighs and torso.

\section{Radiation exposure measurements}

Seven thermoluminescent dosimeters (TLD; UD-802; Panasonic, Osaka, Japan) were used to measure radiation doses. Five of the TLDs were placed on the physician in the following locations during the CEBs: inside the thyroid protector, outside the thyroid protector, inside the lead gown chest area, outside the lead gown chest area, and on the forehead (Fig. 2). Our pain center does not have glass type TLDs, so the forehead dosimeter was used to esti-
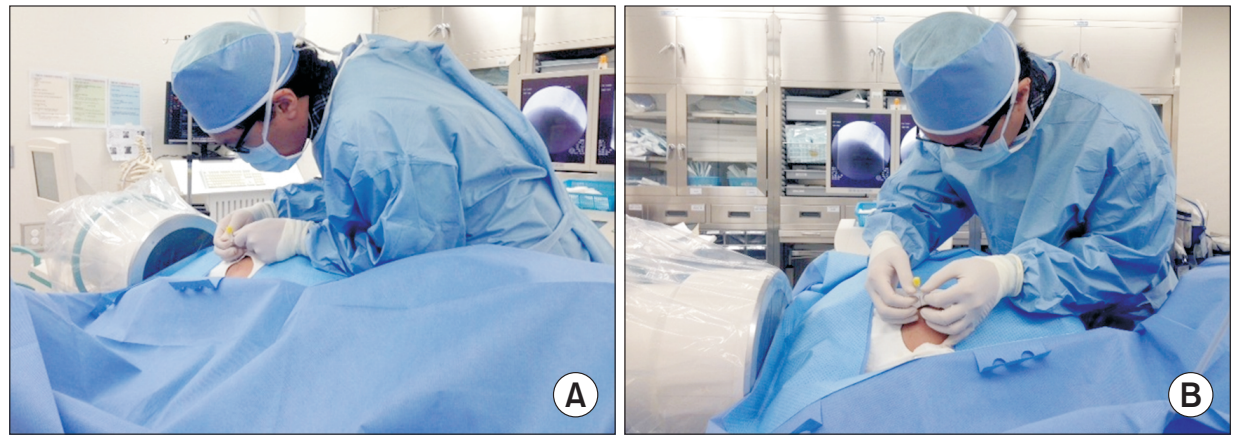

Korean J Pain 2020;33(1):73-80
Fig. 1. The cervical epidural block (CEB) technique. (A) Lateral view of a pain physician performing a CEB. (B) Anterior view of a pain physician performing a CEB. 


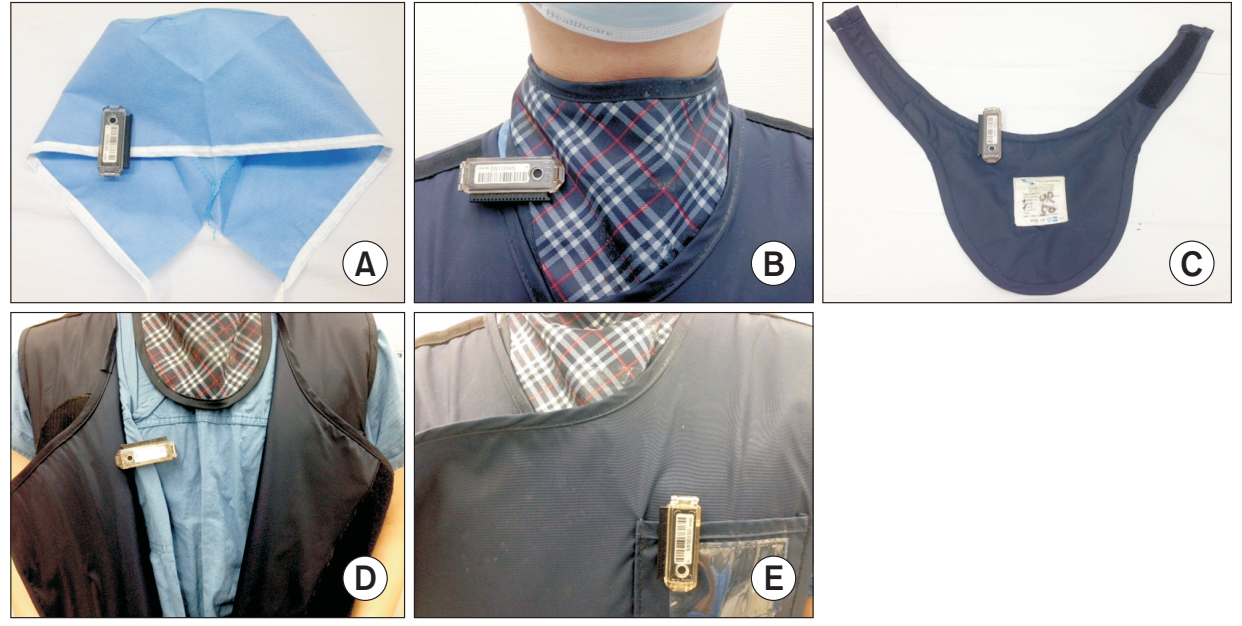

Fig. 2. Thermoluminescent dosimeters were placed on the forehead (A), outside the thyroid protector $(B)$, inside the thyroid protector $(C)$, inside the apron (D), and outside the apron (E). mate ocular radiation exposure. The forehead TLD was placed as close as possible to the physician's eye without obstructing the field of vision. The two remaining TLDs served as control badges and were placed on a wall shelf at a distance of $250 \mathrm{~cm}$ horizontally and $200 \mathrm{~cm}$ vertically from the fluoroscopic table. The others were placed more than $100 \mathrm{~m}$ outside the operating room. Control badges remained in their positions for the full 2-month study period.

Data on the CEB procedural time, radiation exposure time, and radiation absorption dose (RAD) were collected as standard fluoroscopy data (Ziehm Vision; Ziehm Imaging GMBH, Nuremberg, Germany). The distance between the X-ray beam and the physician (Fig. 3) was measured during imaging after needle manipulation. Once the physician positioned himself right next to the patient and got onto the foot stool, he was told to minimize body movement and to not step down from the stool. The pain physician did not wear leaded eyewear and the lead apron, thyroid protector, and 5 physician-placed TLDs were stored outside of the operating room when not in use. Patient age, sex, height, and body weight were also recorded.

\section{CEB}

Before the procedure, an intravenous catheter was placed. All CEBs were fluoroscopy-guided and performed under sterile conditions while vital signs (i.e., blood pressure, pulse oximeter, and electrocardiogram) were monitored. The patient was placed in the prone position on a radiological table, and the pain physician placed himself right next to the patient using a foot stool (the operating bed was positioned in the high optimal fluoroscopy placement). Once placed next to the patient, the pain physician remained on the foot stool. Bending and/or extending of the back and neck and moving of the hands were allowed. The physician was allowed to stay away from the patient while

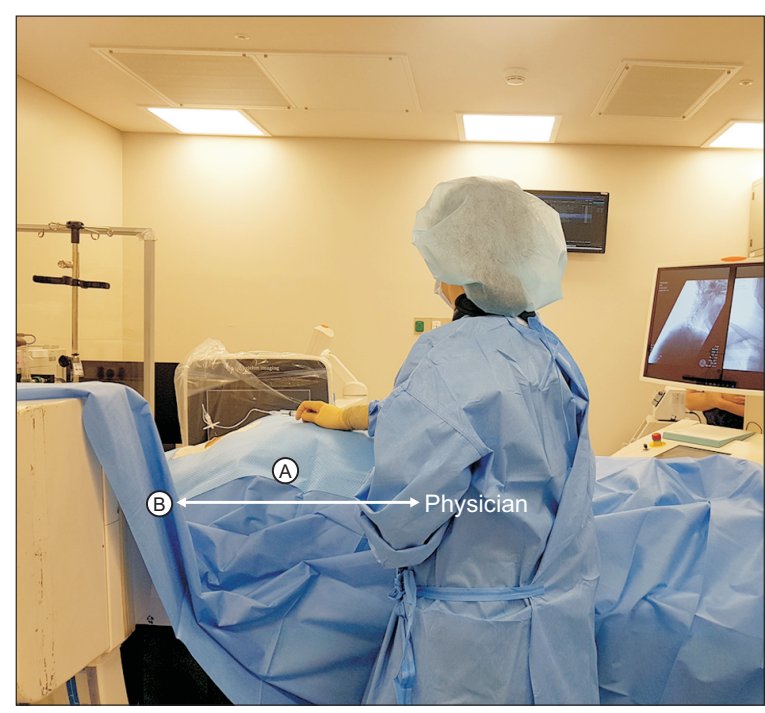

Fig. 3. Measurement of the distance (A) between the center of the X-ray field (B) and the physician. The distance between the X-ray beam and the physician was measured during imaging after needle manipulation.

checking the fluoroscopic image after manipulating the needle. Therefore, the physician only minimally moved his body during the procedure and kept a fairly constant posture. Other than the thyroid protector and lead apron, no other protective devices (e.g., leaded curtain or a leaded glass shield) were worn.

After positioning the patient for fluoroscopy, the site of the skin puncture was locally anesthetized with $1 \%$ lidocaine. A 20-gauge Tuohy Needle (Tae-Chang Industrial Co., Gongju, Korea) was inserted between the C6 and C7 vertebrae using a midline approach determined with anteroposterior fluoroscopy images. When the needle was firmly engaged, positioning was confirmed by examining the lateral view on fluoroscopy. The needle was advanced using a LOR technique in order to identify the epidural space. After obtaining LOR, contrast media (Iohexol, 300 mg iodine/mL; GE Healthcare, Piscataway, NJ) was in- 
jected through the needle for confirmation of position in the cervical epidural space. After all the scout films were checked, radiation exposure time and RAD were measured. It should be noted that real-time fluoroscopy was used in continuous mode during contrast media injection.

\section{Statistical analyses}

In the pilot study of our pain clinic, the radiation dose to which the professor was exposed was $32 \%$ of that to which the fellow was exposed. The pilot study was conducted on C-arm fluoroscopy-guided procedures during a period of 3 months. Our study included fluoroscopy-guided cervical spine procedures, and thus, we expected a higher radiation dose than that in lumbar spine procedures. We expected the radiation dose to which the professor was exposed to be $60 \%$ of that to which the fellow was exposed, approximately. A sample size of 45 patients per group was calculated to be needed, with a significance level of 0.05 $(\alpha=0.05)$ and a power of $80 \%(\beta=0.20)$, allowing for a $10 \%$ drop out rate.

Patient demographic data (age, sex, height, and weight) as well as data on the procedure time, radiation exposure time, absorbed dose, and distance from the X-ray field were collected. Measured radiation doses recorded by the TLDs over 2 months were converted to annual equivalent doses for all analyses. Data are expressed as mean \pm standard deviation, and all statistical analyses were performed using IBM SPSS Statistical software ver. 20.0 (IBM Corp., Armonk, NY). The $t$-tests were used to determine the statistical significance of differences in means. Statistical significance was defined as $P<0.05$.

Table 1. Patient Demographics and Radiation-related Procedural Data

\begin{tabular}{lccc}
\hline \multicolumn{1}{c}{ Variable } & $\begin{array}{c}\text { Fellow } \\
(\mathrm{n}=50)\end{array}$ & $\begin{array}{c}\text { Professor } \\
(\mathrm{n}=50)\end{array}$ & $P$ value \\
\hline Age $(\mathrm{yr})$ & $56.6 \pm 12.4$ & $54.2 \pm 11.3$ & 0.96 \\
Sex $(\mathrm{male} /$ female) & $26 / 24$ & $27 / 23$ & \\
Height $(\mathrm{cm})$ & $163.1 \pm 7.9$ & $168.1 \pm 1.3$ & 0.21 \\
Weight $(\mathrm{kg})$ & $63.1 \pm 12.6$ & $66.2 \pm 6.1$ & 0.27 \\
Total time of procedure (min) & $13.3 \pm 1.7$ & $10.6 \pm 1.3$ & 0.35 \\
$\begin{array}{l}\text { Time of radiation exposure/ } \\
\quad \text { procedure (sec) }\end{array}$ & $22.9 \pm 8.8$ & $17.7 \pm 2.4$ & 0.18 \\
$\begin{array}{l}\text { Radiation dose/procedure } \\
\quad\left(\mathrm{cGy} / \mathrm{cm}^{2} \text { ) }\right.\end{array}$ & $-95.4 \pm 66.1$ & $89.9 \pm 13.3$ & 0.16 \\
$\begin{array}{l}\text { Physician distance from } \\
\text { radiation beam (cm) }\end{array}$ & $37.5 \pm 2.1$ & $-41.2 \pm 3.6$ & 0.03 \\
\hline
\end{tabular}

Values are presented as the mean \pm standard deviation or number only.

\section{RESULTS}

In total, $100 \mathrm{CEB}$ procedures were performed on 100 patients during the 2-month study period. Fifty cases were performed by the fellow and 50 cases were performed by the professor. Patient demographic data is summarized in Table 1. The CEB procedural time, radiation exposure time, and radiation absorption time were not significantly different between the two physicians. However, the distance from the $\mathrm{X}$-ray field to the physician was significantly greater for the professor than for the fellow $(P=0.03)$.

The forehead TLD indicated a radiation exposure of 0.74 and $0.62 \mathrm{mSv}$ for the fellow and professor, respectively. The radiation dose recorded on the outside of the lead apron (fellow: $0.71 \mathrm{mSv}$, professor: $0.64 \mathrm{mSv}$ ) was similar to that recorded at the forehead for both physicians (Table 2). The TLDs placed on the inside of the apron showed radiation exposure values similar to those of the control TLD, but the TLDs placed inside the thyroid protector had slightly higher readings than did the control TLD. Therefore, lead-based protection provided a reduction in radiation exposure by $22 \%-35 \%$, reducing exposure to levels near those of the control TLDs (Table 2). All exposure values from the 2-month period were scaled up to determine the equivalent radiation exposure for $600 \mathrm{CEB}$ procedures, our center's approximate annual CEB number per physician. All exposure values were well below the annual acceptable radiation exposure dose established by the ICRP (Fig. 4).

\section{DISCUSSION}

Fluoroscopy is widely used in interventional pain management procedures. As a result, studies concerning the radi-

Table 2. Radiation Dose Measured with Thermoluminescent Dosimeters (TLDs)

\begin{tabular}{llcc}
\hline Physician & \multicolumn{1}{c}{ TLD position } & $\begin{array}{c}\text { Radiation } \\
\text { dose }(\mathrm{mSv})\end{array}$ & $\begin{array}{c}\text { Radiation } \\
\text { reduction with } \\
\text { protection (\%) }\end{array}$ \\
\hline Fellow & Forehead & 0.74 & \\
& Outside of thyroid protector & 0.55 & \\
& Inside of thyroid protector & 0.43 & 22 \\
& Outside of apron & 0.71 & \\
\multirow{3}{*}{ Professor } & Inside of apron & 0.47 & 34 \\
& Forehead & 0.62 & \\
& Outside of thyroid protector & 0.47 & \\
& Inside of thyroid protector & 0.32 & 32 \\
& Outside of apron & 0.64 & \\
& Inside of apron & 0.42 & 35 \\
Control & Inside operating room & 0.40 & \\
& Outside operating room & 0.37 & \\
\hline
\end{tabular}




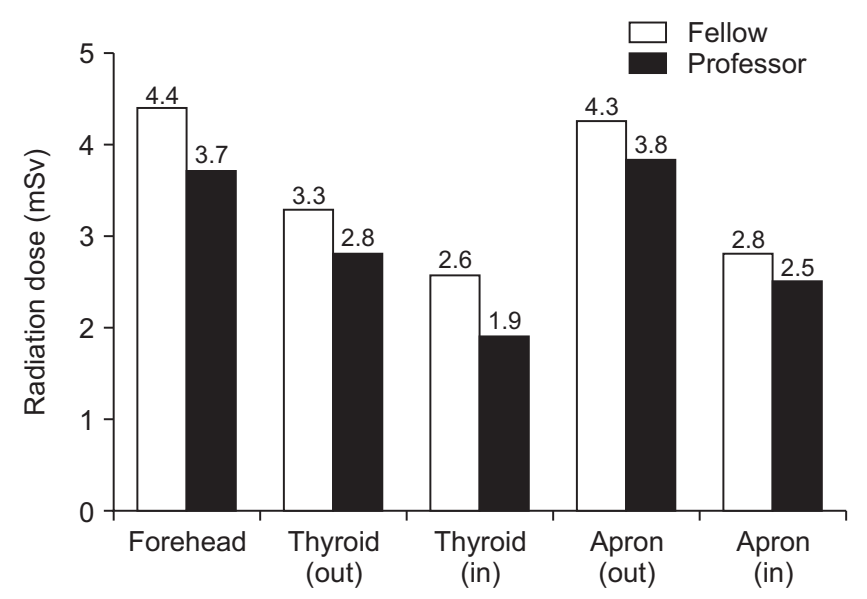

Fig. 4. Annual equivalent dose (approximately 600 cases) was calculated from 2-month (100 cases) exposure data, as measured using thermoluminescent dosimeters. Annual maximum permissible radiation doses set by the International Commission on Radiological Protection are 500 and $20 \mathrm{mSv}$ for the thyroid and crystalline lens, respectively. In: inside, Out: outside.

ation exposure of pain physicians are now being published $[21,22]$. Fortunately, most studies regarding radiation exposure during fluoroscopy-guided interventions have concluded that exposure levels are well below the yearly limit established by the ICRP [23-25]. However, exposure to low levels of ionizing radiation over the long-term cannot be accurately predicted. These long-term, low-level ionizing radiation exposures may not acutely destroy cells, but may lead to cell damage and genetic mutations that can lead to sequelae years later [3]. Epidemiologic studies from the Hiroshima, Nagasaki, and Chernobyl nuclear disasters revealed that low-dose radiation exposure may lead to early cataract development [12-14]. Therefore, pain physicians should understand the risks associated with radiation exposure during fluoroscopy-guided interventions and take proper precautions to minimize occupational radiation exposure.

We chose to examine radiation exposure during the CEB for several reasons. The CEB would be associated with more radiation exposure compared with other procedures because, in our hospital, the CEB is carried out in close proximity to the radiation beam, although we acknowledge that the procedures followed by pain physicians differ. In our study, the distance between the physician and the X-ray field was only $37.5 \pm 2.1 \mathrm{~cm}$ (Table 1) for the fellow. Such proximity may increase the physician's radiation exposure because radiation that scatters off the patient's body is more likely to reach the pain physician's head [26]. Indeed, we found that the forehead TLD recorded the highest radiation dose, reaching exposure levels as high as $4.44 \mathrm{mSv} / \mathrm{yr}$ (converted from 100 cases over 2 months to approximately 600 cases over 1 yr; Fig. 4).
Both examined physicians had similar radiation exposures on the forehead and outside of the apron. In contrast, the TLD placed outside of the thyroid protector recorded values almost as low as those recorded inside the apron. This unusual result may be explained by the habit of pain physicians flexing their heads to better visualize an injection site. This results in tucking of the chin, possibly blocking the thyroid from radiation exposure. Although higher compared to the control and lead-protected TLDs, other TLDs located outside of lead-based protective devices, even the forehead TLD, had radiation exposures well below ICRP limits. The physicians participating in this study did not wear leaded eyewear protection because many pain physicians refrain from wearing protective eye gear during procedures, and we wanted our results to be representative of the usual clinical setting.

Our secondary objective was to examine the efficacy of lead-based protection gear and whether or not it affected radiation exposure in the clinical setting. In our study, a lower radiation dose was measured in the TLDs placed inside of the lead-based protection gear compared with the outer TLDs (Table 2). Therefore, we conclude that lead-based protective gear is effective and stress the importance of shielding in keeping pain physician radiation exposure to a minimum.

The ICRP has three main principles for reducing unnecessary occupational radiation exposure, which are justification, optimization, and dose limitation [20]. Justification ensures that "more good is done than harm" when using harmful radiation. Optimization means that radiation doses should be kept "as low as possible," and should consider social, medical, and economic implications. Dose limitation involves the three factors of time, distance, and shielding [27].

Reducing exposure time proportionally decreases radiation. Skilled physicians generally perform procedures more quickly and have the advantage of reduced exposure time. In our study, the radiation exposure time of the professor was shorter than that of the fellow, but this difference was not statistically significant. However, the distance between the X-ray field and the professor was significantly greater than the distance between the fellow and the X-ray field. Given that radiation exposure is inversely proportional to the square of the distance, inexperienced pain physicians should be educated on the importance of radiation safety, which includes keeping as large a distance from the X-ray field as possible.

The term "shielding" literally means to shield one's body from the radiation rays, usually by wearing leaded products (e.g., aprons, gloves, and goggles). Leaded aprons that are $0.5 \mathrm{~mm}$ thick are known to reduce radiation exposure by up to $99 \%$ [28], and leaded eyewear is known to 
reduce radiation exposure by up to $70 \%$ [29]. However, we observed much lower protection rates in the current study (lead apron: $34 \%-35 \%$, thyroid protector: $22 \%-32 \%$ ). This may have resulted from the thinner apron $(0.3 \mathrm{~mm}$ lead in the front) used by our hospital and from possible defects in our protective lead-based gear. In support of the product defect theory, Oyar and Kışlalığlu [30] found that, in his hospital, only $15.3 \%$ of the aprons were providing normal protection levels and that $68.2 \%$ of aprons were not stored and cared for properly. In fact, even normally-functioning aprons had folds and creases, causing leaks where radiation could enter. Unfortunately, our study physicians did not use new aprons or thyroid protectors. Therefore, it is possible that the thyroid protectors and lead aprons used in the current study could have had defects, causing a skewing of our results.

Many physicians are not properly educated on the importance of protective equipment and the harm that occupational radiation exposure can cause [31-33]. A pilot study on fellows with at least one year of clinical practice experience showed that a mere $33 \%$ of physicians had received proper radiation safety training. The importance of radiation safety training was evident because the educated group was more likely to use protective gear [34]. The use of gear in an educational environment is particularly important because radiation exposure time has been estimated to be 2-14 times higher than that in environments where only experienced physicians perform procedures [35].

Our study showed that eyes are more susceptible than the thyroid to radiation. This concurs with the ICRP's recent decision to lower the yearly maximum radiation dose to the eye from 150 to $20 \mathrm{mSv}$. In contrast to apron and thyroid protectors, which are widely used among pain physicians, the actual use of leaded eyewear is unknown. During fluoroscopy-guided procedures, pain physicians almost always place themselves near the patient, increasing the risk of ocular radiation exposure from scattered radiation from the patient. Thus, the use of leaded eyewear must be enforced. Furthermore, the ideal position of the physician's head to minimize ocular radiation exposure would be 90 degrees from the scattered radiation. Without optimal head positioning, leaded eyewear may be useless. Therefore, appropriate tilting of the head should also be considered [36]. In conclusion, the use of lead-based protection must be enforced, and clinical experience affects physician radiation, specifically because inexperienced physicians position themselves closer to the radiation beam.

The main limitation of our study was that radiation exposure was only examined during the CEB procedure. Radiation exposure during only one type of procedure is likely not representative of the annual radiation dose for pain physicians performing multiple fluoroscopy-guided techniques at multiple hospitals. Further research including a variety of techniques would give a more realistic annual radiation dose. In addition, our study calculated annual radiation doses using only two months of data. Further studies that collect radiation exposure data over a full year are needed.

There was a difference in the distance to the X-ray field during the procedure but no significant difference in the radiation exposure between the professor and the fellow during the CEBs. Even though the distance between the $\mathrm{X}$-ray beam and the pain physician is small, radiation exposure can be minimized if proper protectors (thyroid protector, leaded apron, and eyewear) are worn. Further, we should consider that exposure to radiation varies depending on the physical condition of the pain physician and the method of the procedure. However, it remains uncertain whether or not long-term health effects occur from frequent low-dose radiation exposure, and safety precautions must always be followed.

\section{CONFLICT OF INTEREST}

No potential conflict of interest relevant to this article was reported.

\section{FUNDING}

No funding to declare.

\section{ORCID}

Eun Joo Choi, https://orcid.org/0000-0002-7002-3932 Gwangcheol Go, https://orcid.org/0000-0002-7469-6392

Woong Ki Han, https://orcid.org/0000-0002-6894-9787

Pyung-Bok Lee, https://orcid.org/0000-0003-0325-3356

\section{REFERENCES}

1. Manchikanti L, Singh V, Hirsch JA. Saga of payment systems of ambulatory surgery centers for interventional techniques: an update. Pain Physician 2012; 15: 109-30.

2. Vera GV, Aleksandra F, Dragan K, Andrija H. Assessment of genome damage in occupational exposure to ionising radiation and ultrasound. Mutat Res 1997; 395: 101-5.

3. Andreassi MG. The biological effects of diagnostic cardiac imaging on chronically exposed physicians: the importance 
of being non-ionizing. Cardiovasc Ultrasound 2004; 2: 25.

4. Maffei F, Angelini S, Forti GC, Violante FS, Lodi V, Mattioli $\mathrm{S}$, et al. Spectrum of chromosomal aberrations in peripheral lymphocytes of hospital workers occupationally exposed to low doses of ionizing radiation. Mutat Res 2004; 547: 91-9.

5. Krempen JF, Smith BS. Nerve-root injection: a method for evaluating the etiology of sciatica. J Bone Joint Surg Am 1974; 56: 1435-44.

6. White $\mathrm{AH}$. Injection techniques for the diagnosis and treatment of low back pain. Orthop Clin North Am 1983; 14: 55367.

7. Bicket MC, Gupta A, Brown CH 4th, Cohen SP. Epidural injections for spinal pain: a systematic review and metaanalysis evaluating the "control" injections in randomized controlled trials. Anesthesiology 2013; 119: 907-31.

8. Candido KD, Knezevic NN. Cervical epidural steroid injections for the treatment of cervical spinal (neck) pain. Curr Pain Headache Rep 2013; 17: 314.

9. Bose B. Quadriparesis following cervical epidural steroid injections: case report and review of the literature. Spine J 2005; 5: 558-63.

10. Hodges SD, Castleberg RL, Miller T, Ward R, Thornburg C. Cervical epidural steroid injection with intrinsic spinal cord damage. Two case reports. Spine (Phila Pa 1976) 1998; 23: 2137-42.

11. Khan S, Pioro EP. Cervical epidural injection complicated by syrinx formation: a case report. Spine (Phila Pa 1976) 2010; 35: E614-6.

12. Nakashima E, Neriishi K, Minamoto A. A reanalysis of atomic-bomb cataract data, 2000-2002: a threshold analysis. Health Phys 2006; 90: 154-60.

13. Neriishi K, Nakashima E, Minamoto A, Fujiwara S, Akahoshi M, Mishima HK, et al. Postoperative cataract cases among atomic bomb survivors: radiation dose response and threshold. Radiat Res 2007; 168: 404-8.

14. Vano E. Radiation exposure to cardiologists: how it could be reduced. Heart 2003; 89: 1123-4.

15. Ciraj-Bjelac O, Rehani MM, Sim KH, Liew HB, Vano E, Kleiman NJ. Risk for radiation-induced cataract for staff in interventional cardiology: is there reason for concern? Catheter Cardiovasc Interv 2010; 76: 826-34.

16. Vano E, Kleiman NJ, Duran A, Rehani MM, Echeverri D, Cabrera M. Radiation cataract risk in interventional cardiology personnel. Radiat Res 2010; 174: 490-5.

17. Chodick G, Bekiroglu N, Hauptmann M, Alexander BH, Freedman DM, Doody MM, et al. Risk of cataract after exposure to low doses of ionizing radiation: a 20-year prospective cohort study among US radiologic technologists. Am J Epidemiol 2008; 168: 620-31.

18. Rehani MM, Vano E, Ciraj-Bjelac O, Kleiman NJ. Radiation and cataract. Radiat Prot Dosimetry 2011; 147: 300-4.

19. Stewart FA, Akleyev AV, Hauer-Jensen M, Hendry JH, Klei- man NJ, Macvittie TJ, et al. ICRP publication 118: ICRP statement on tissue reactions and early and late effects of radiation in normal tissues and organs--threshold doses for tissue reactions in a radiation protection context. Ann ICRP 2012; 41: 1-322.

20. The 2007 Recommendations of the International Commission on Radiological Protection. ICRP publication 103. Ann ICRP 2007; 37: 1-332.

21. Manchikanti L, Cash KA, Moss TL, Pampati V. Radiation exposure to the physician in interventional pain management. Pain Physician 2002; 5: 385-93.

22. Jung CH, Ryu JS, Baek SW, Oh JH, Woo NS, Kim HK, et al. Radiation exposure of the hand and chest during C-arm fluoroscopy-guided procedures. Korean J Pain 2013; 26: 51-6.

23. Botwin KP, Freeman ED, Gruber RD, Torres-Rames FM, Bouchtas CG, Sanelli JT, et al. Radiation exposure to the physician performing fluoroscopically guided caudal epidural steroid injections. Pain Physician 2001; 4: 343-8.

24. Botwin KP, Fuoco GS, Torres FM, Gruber RD, Bouchlas CC, Castellanos R, et al. Radiation exposure to the spinal interventionalist performing lumbar discography. Pain Physician 2003; 6: 295-300.

25. Botwin KP, Thomas S, Gruber RD, Torres FM, Bouchlas CC, Rittenberg JJ, et al. Radiation exposure of the spinal interventionalist performing fluoroscopically guided lumbar transforaminal epidural steroid injections. Arch Phys Med Rehabil 2002; 83: 697-701.

26. Politi L, Biondi-Zoccai G, Nocetti L, Costi T, Monopoli D, Rossi $\mathrm{R}$, et al. Reduction of scatter radiation during transradial percutaneous coronary angiography: a randomized trial using a lead-free radiation shield. Catheter Cardiovasc Interv 2012; 79: 97-102.

27. Paulson EK, Sheafor DH, Enterline DS, McAdams HP, Yoshizumi TT. CT fluoroscopy--guided interventional procedures: techniques and radiation dose to radiologists. Radiology 2001; 220: 161-7.

28. Singer G. Occupational radiation exposure to the surgeon. J Am Acad Orthop Surg 2005; 13: 69-76.

29. Richman AH, Chan B, Katz M. Effectiveness of lead lenses in reducing radiation exposure. Radiology 1976; 121: 357-9.

30. Oyar O, Kışlalıoğlu A. How protective are the lead aprons we use against ionizing radiation? Diagn Interv Radiol 2012; 18: 147-52.

31. Bordoli SJ, Carsten CG 3rd, Cull DL, Johnson BL, Taylor SM. Radiation safety education in vascular surgery training. J Vasc Surg 2014; 59: 860-4.

32. Friedman AA, Ghani KR, Peabody JO, Jackson A, Trinh QD, Elder JS. Radiation safety knowledge and practices among urology residents and fellows: results of a nationwide survey. J Surg Educ 2013; 70: 224-31.

33. Cheon BK, Kim CL, Kim KR, Kang MH, Lim JA, Woo NS, et al. Radiation safety: a focus on lead aprons and thyroid shields 
in interventional pain management. Korean J Pain 2018; 31: 244-52.

34. Park PE, Park JM, Kang JE, Cho JH, Cho SJ, Kim JH, et al. Radiation safety and education in the applicants of the final test for the expert of pain medicine. Korean J Pain 2012; 25: $16-21$.

35. Zhou Y, Singh N, Abdi S, Wu J, Crawford J, Furgang FA. Fluo- roscopy radiation safety for spine interventional pain procedures in university teaching hospitals. Pain Physician 2005; 8: 49-53.

36. Cousin AJ, Lawdahl RB, Chakraborty DP, Koehler RE. The case for radioprotective eyewear/facewear. Practical implications and suggestions. Invest Radiol 1987; 22: 688-92. 